\title{
Analisis Kelayakan Penggantian Insulator Jaringan Pipa Penyalur Uap PLTP Darajat Milik Chevron Geothermal Indonesia
}

\author{
Lutvin Susdiawan P. ${ }^{1, a)}$, Octhafian Wahyu Irawan ${ }^{2, b)}$, Erwin Perdana. ${ }^{3, c)}$ \\ 1,2,3Program Studi Teknik Mesin ITI, \\ Jl. Raya Puspiptek Serpong, Tangerang Selatan-Banten, Indonesia, 15320

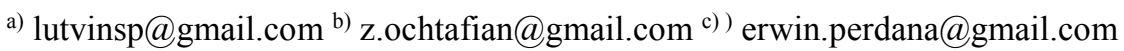

\begin{abstract}
Abstrak
Energi panas bumi sering diasosiasikan dengan istilah green energy karena seluruh proses pembangkitan energi listrik sangat ramah lingkungan. Penggunaan bahan isolasi alumunium cladding pada pipa uap untuk sumber energi panas bumi mengakibatkan perusahaan mengalami kerugian 2.6 juta USD per tahun atau 20.800.000 USD untuk operasi selama 8 tahun. Agar terjadi efisiensi pemanfaatan energi maka rugi-rugi panas yang terjadi harus sekecil mungkin. Oleh karena itu dilakukan kajian terhadap bahan isolasi pengganti aluminum cladding guna meminimalisir panas yang hilang serta kerugian pendapatan. Dengan mengganti bahan isolasi pipa dengan bahan rockwool dan calcium silicate maka dapat meminimalisir rugi-rugi panas serta kerugian pendapatan perusahaan untuk kurun waktu operasi 8 tahun.
\end{abstract}

Kata kunci: energi panas bumi, isolasi pipa, rugi-rugi panas

\begin{abstract}
Geothermal energy is often associated with the term green energy because the entire process of generating electrical energy is very environmentally friendly. The alumunium cladding pipe insulatin used on geothermal energy source has made the company suffered a loss of 2.6 million USD per year or 20,800,000 USD for 8 years operation. In order to achieve efficiency in energy utilization, the heat loss must be minimum. Therefore, a study of the insulation material to replace aluminum cladding in order to minimize heat loss and income losses is needed. By replacing the pipe insulation materials with rockwool and calcium silicate, the total heat loss and total loss of company revenue in the period of 8 years operation can be minimized.
\end{abstract}

Keywords: green energy, heatloss, pipe insulation

\section{PENDAHULUAN}

Uap panas merupakan sumber utama dalam mengolah produksi, aliran uap panas yang melalui pipa selalu dipengaruhi oleh udara bebas [1]. Selama ini banyak industri yang melindungi pipa tersebut dengan isolasi namun mengabaikan perhitungan kehilangan panas yang terjadi dalam aliran pipa uap tersebut, akibatnya perusahaan tidak mengetahui berapa banyak uap yang terbuang ke udara selama mengalir pada saluran pipa uap dan tentunya pemanfaatan uap tersebut untuk produksi kurang maksimal. Oleh karena itu perlu dilakukan pemilihan jenis mineral wool, calcium silicate, dan ceramic fiber blanket yang sering banyak digunakan, dengan cara membuat simulasi dalam keadaan steady untuk menentukan bahan yang paling tepat dalam mengurangi kehilangan panas [2].

\section{LANDASAN TEORI}

\section{A. Dasar teori perpindahan panas}

Proses perpindahan panas atau perpindahan kalor dapat terjadi dalam tiga macam cara yaitu:

1. Radiation, adalah perpindahan panas yang tidak memerlukan perantara.
2. Conduction, adalah perpindahan panas melalui perantara, contohnya seperti logam yang dipanaskan.

3. Convection, adalah perpindahan panas yang terjadi disertai zat perantara.

\section{B. Tujuan pemakaian isolasi [3]}

Tujuan isolasi pipa penyalur uap adalah sebagai berikut:

1. Meningkatkan Efisiensi Proses, Isolasi menjaga agar terjadinya proses perpindahan panas pada pipa dan juga equipment ke lingkungan atau sebaliknya (pipa dingin) dapat dikurangi.

2. Keselamatan, isolasi akan menghindarkan sentuhan langsung dengan pipa atau equipment panas oleh operator.

3. Untuk melindungi equipment, kabel-kabel yang sensitif terhadap panas.

\section{Material isolasi pipa}

Pemilihan material harus memperhatikan karakteristik material yakni density dan ketebalan yang diperlukan sesuai spesifikasi rating desain [4]. Material isolasi pipa yakni: 
1. Bahan isolasi kalsium silikat

2. Bahan isolasi fiber glass

3. Bahan isolasi cellular glass

4. Bahan isolasi mineral fiber

D. Aplikasi perpindahan panas pada pipa penyalur

Thermal resistance dapat dipakai untuk menyelesaikan masalah-masalah perpindahan panas tunak dengan arah satu dimensi (steady one dimensional heat transfer) [5]. Gambar 1 memperlihatkan pipa uap dibungkus dengan tiga lapisan isolasi yang berbentuk komposit silinder dengan panjang L [6]. Perpindahan panas terjadi secara konveksi dan konduksi. Secara ekspresi matematis, laju perpindahan panas Q (kW) yang terjadi telah di formulasikan sebagai berikut:
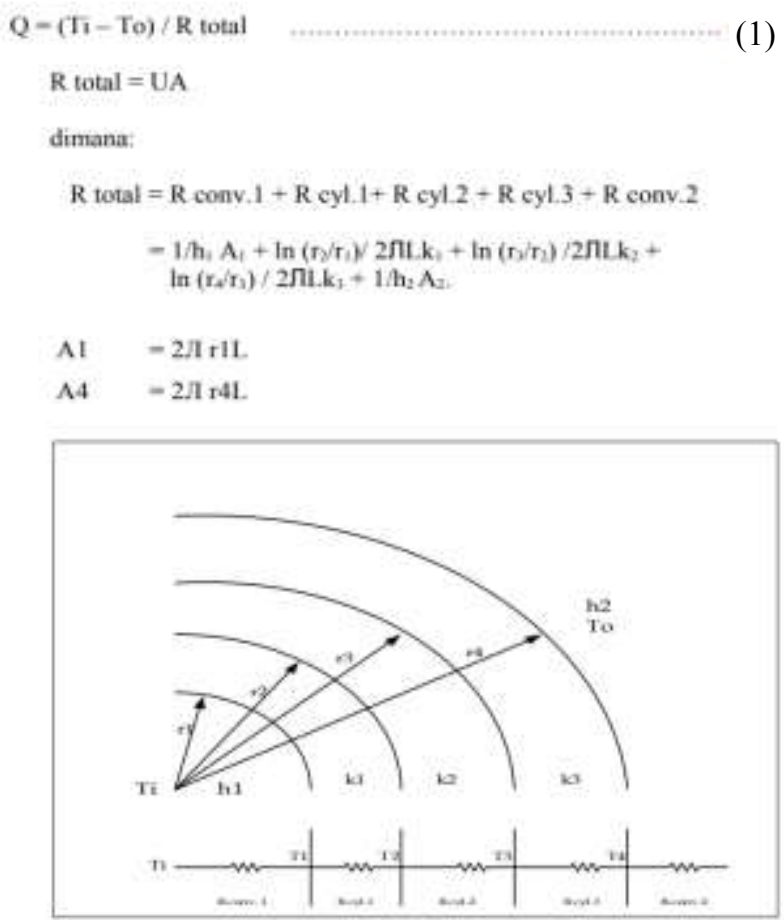

Gambar 1. Diagram isolasi pipa

\section{E. Bahan isolasi alumunium cladding}

Pipa penyalur uap di lapangan Darajat dirancang menggunakan sistem isolasi pembungkus udara. Pipa di bungkus dengan alumunium cladding dengan diameter 5 inch lebih besar dari ukuran pipa.

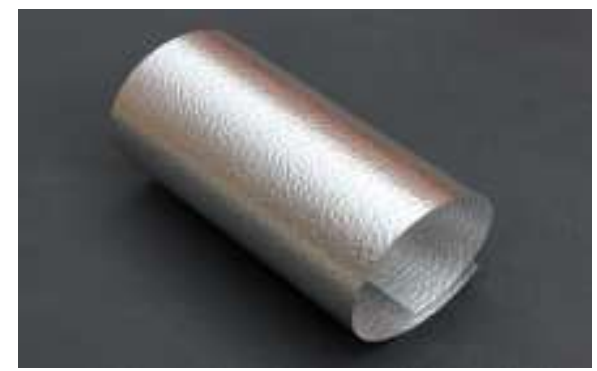

Gambar 2. Aluminum cladding

\section{F. Bahan isolasi calcium silicate}

Calcium silicate adalah sejenis bahan insulasi yang memiliki karakteristik ringan, konduktifitas termal yang rendah, dan mampu untuk menahan tempratur tinggi. Bahan yang memiliki nama singkat cal-sil ini dipasarkan dalam tiga bentuk yakni balok, pipa, atau lembaran.

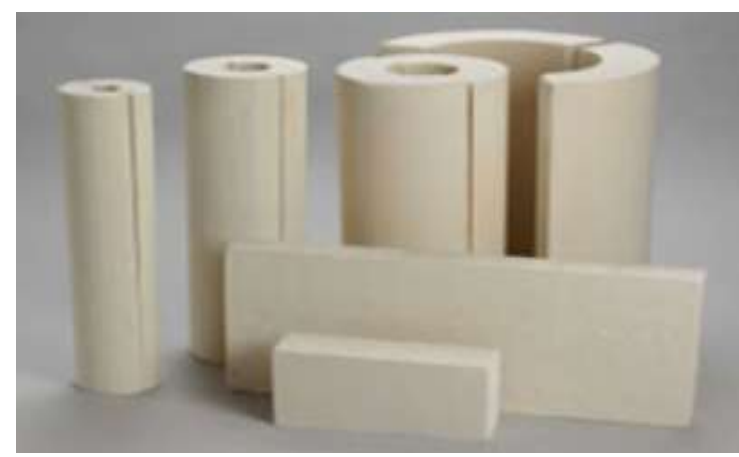

Gambar 3. Calcium silicate

\section{G. Bahan isolasi rockwool}

Rockwool terbuat dari bahan anorganik dan tidak bernutrisi sehingga terbebas dari mikroorganisme. Wol mineral tidak akan membusuk dan bebas kutu. Sangat cocok untuk isolasi suhu, perlindungan kebakaran dan pengurangan/penyerapan [7].

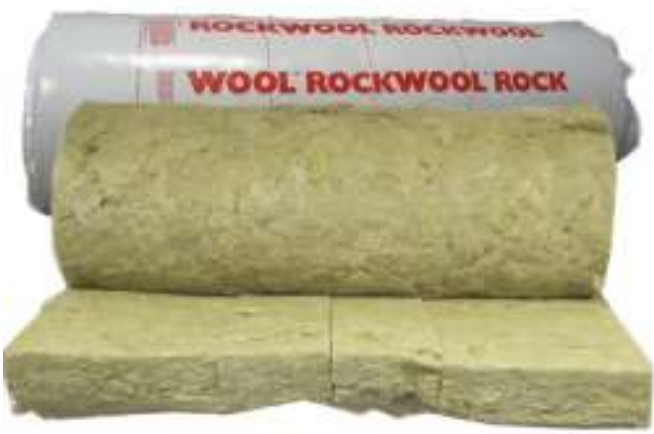

Gambar 4. Rockwool

\section{H. Proses terbentuknya uap panas bumi}

Proses terbentukya uap panas bumi dapat dijelaskan. Magma yang berada dilapisan permukaan bumi memanaskan air permukaan yang meresap kebawah permukaan selayaknya sebuah kompor memanaskan air di dalam ketel uap. Proses perpindahan panas dari magma ke air dapat terjadi dalam bentuk konveksi melalui fluida itu sendiri dan dalam bentuk konduksi yang dihantarkan melalui media bebatuan. Pemanasan yang terus menerus menyebabkan air berubah menjadi fasa uap. Apabila uap ini terperangkap dibawah bebatuan yang tidak permeable maka terbentuklah reservoir uap. Oleh karena proses pembentukan reservoir panas bumi tipikal dengan proses pembentukan uap didalam ketel uap maka semua sifat 
uap yang terbentuk sama dengan sifat-sifat uap khusus [8].

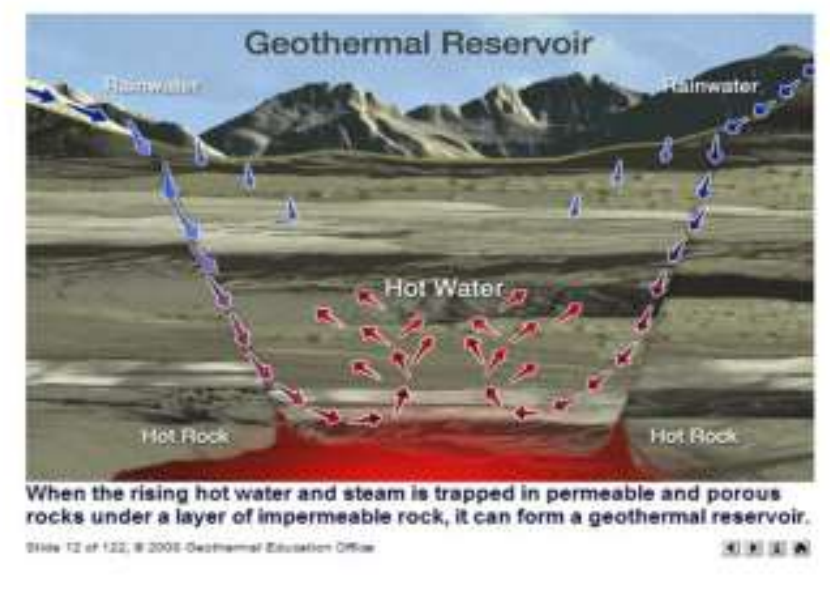

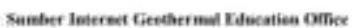

Gambar 5. Proses terbentuknya uap panas bumi

\section{METODE PENELITIAN/EKSPERIMEN}

Diagram alir metodologi penelitian ditunjukkan pada Gambar 6.

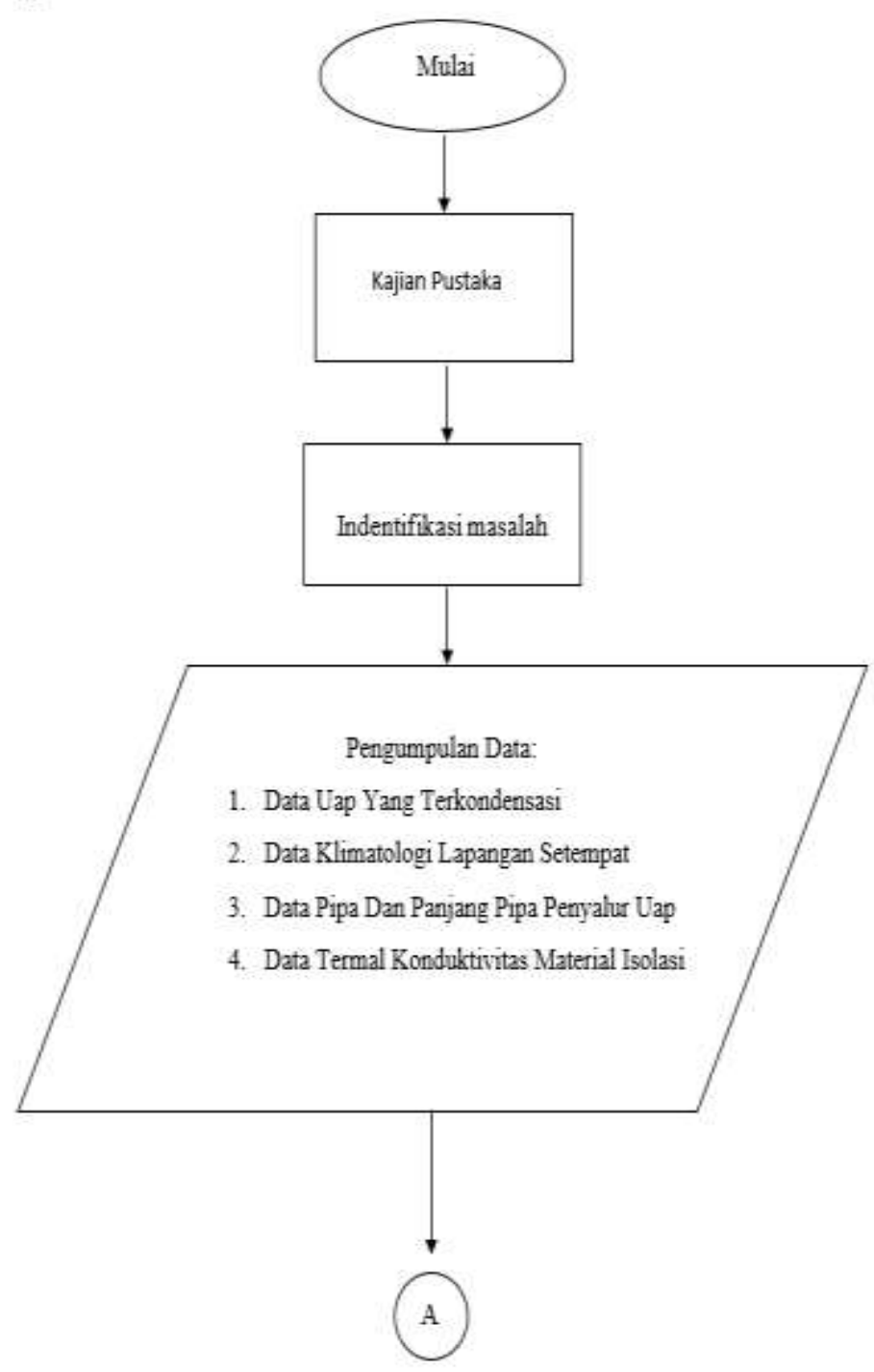

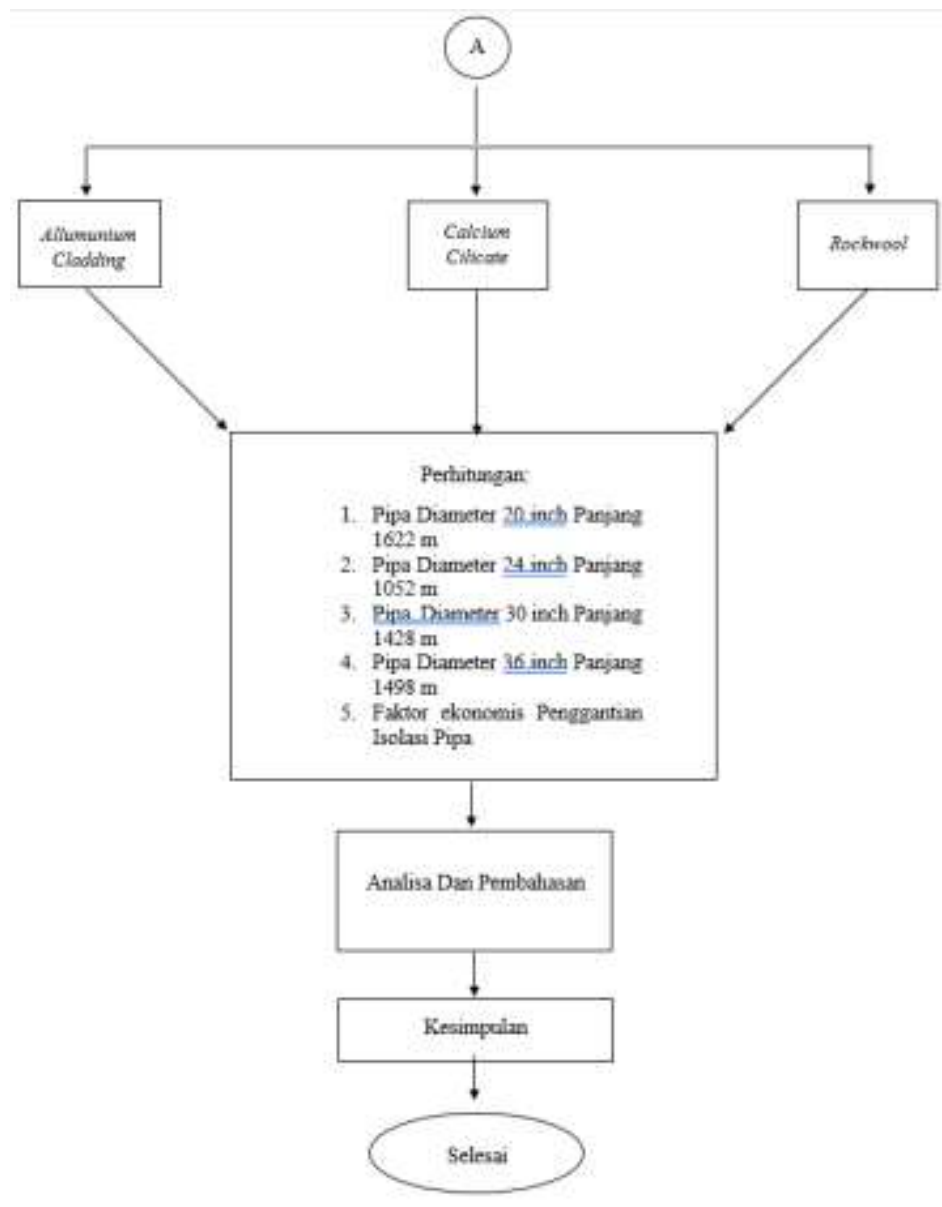

Gambar 6. Diagram alir

IV. HASIL DAN PEMBAHASAN

A. Data pipa yang dihitung

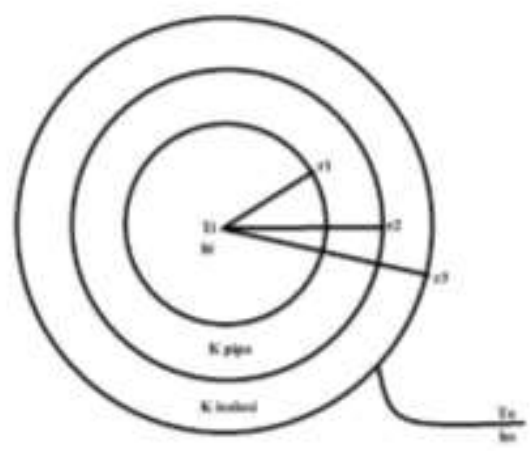

Gambar 6. Isolasi pipa

Pipa yang akan dihitung adalah pipa-pipa dengan diamater 20 inch dengan panjang $1622 \mathrm{~m}$, pipa diameter 24 inch dengan panjang $1052 \mathrm{~m}, 30$ inch dengan panjang $1428 \mathrm{~m}$, dan pipa diameter 36 inch dengan panjang $1498 \mathrm{~m}$. Lalu setelah itu memilih material isolasi baru yang akan dipakai serta memilih nilai konduktivitas termalnya seperti ditunjukkan pada Tabel 1. Material yang dipilih adalah calcium cilicate dengan $\mathrm{K}=0.045 \mathrm{~W} / \mathrm{mK}$ dan rockwool dengan $\mathrm{K}=$ 0.296 karena memiliki nilai konduktivitas termal yang 
rendah sehingga dapat meminimalisir rugi-rugi panas dan kerugian pendapatan .

Tabel 1. Konduktivtitas termal material isolasi

\begin{tabular}{cccc}
\hline $\begin{array}{c}\text { Physical } \\
\text { Properties }\end{array}$ & Rockwoll & $\begin{array}{c}\text { Calcium } \\
\text { Silicate }\end{array}$ & Perlite \\
\hline $\begin{array}{c}\text { Strandard } \\
\text { Spesification }\end{array}$ & ASTM & ASTM C533 & ASTM C610-99 \\
\hline $\begin{array}{c}\text { Max service } \\
\text { temperature }\end{array}$ & $45-600$ & $45-720$ & $260-720$ \\
\hline & 1000.0257 & 2000.045 & 2000.055 \\
Thermal & 2000.0296 & 3000.05 & 3000.06 \\
conductivity & 3000.0354 & 4000.055 & 4000.066 \\
& 4000.0428 & 5000.06 & 5000.074 \\
& 5000.0525 & 6000.066 & 6000.08 \\
& 6000.0637 & 7000.071 & 7000.088
\end{tabular}

a) Rugi-rugi panas bahan isolasi aluminum cladding

$>$ Pipa diameter 20 inch dan panjang $1622 \mathrm{~m}$; Diketahui:

- $\mathrm{D} 1=20$ inch $=0.508 \mathrm{~m}$

- $\mathrm{K}$ pipa $=0.05 \mathrm{~W} / \mathrm{mK}$

- $\mathrm{r} 1=10 \mathrm{inch}=0.254 \mathrm{~m}$

- $\mathrm{K}$ aluminum cladding $=0.05 \mathrm{~W} / \mathrm{mK}$

- $\mathrm{D} 2=22$ inch $=0.558 \mathrm{~m}$

- $\mathrm{r} 2=11 \mathrm{inch}=0.279 \mathrm{~m}$

- $\mathrm{D} 3=25$ inch $=0.635 \mathrm{~m}$

- $\mathrm{r} 3=12.5$ inch $=0.317 \mathrm{~m}$

- $\mathrm{Ti}=513^{\circ} \mathrm{K}$

- $\mathrm{hi}=35 \mathrm{~W} / \mathrm{mK}$

- $\mathrm{To}=291^{\circ} \mathrm{K}$

- ho $=9.5 \mathrm{~W} / \mathrm{mK}$

Perhitungan:

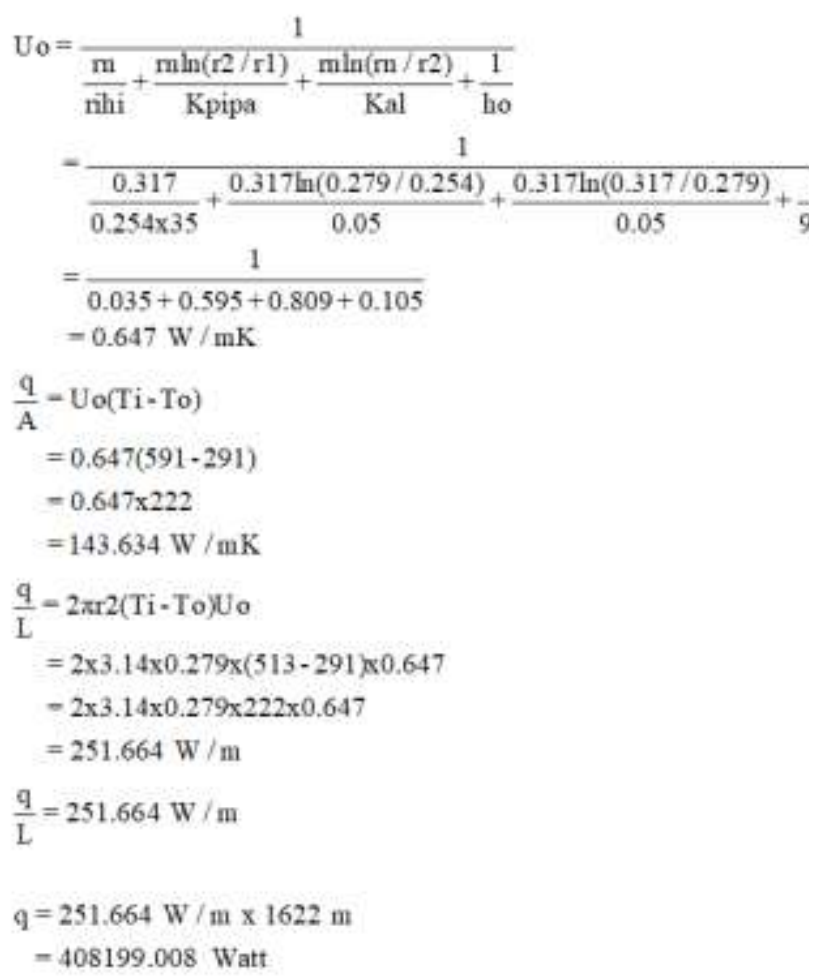

Pipa diameter 24 dan panjang 1052 m;
Diketahui:

- $\mathrm{D} 1=24$ inch $=0.609 \mathrm{~m}$

- $\mathrm{K}$ pipa $=0.05 \mathrm{~W} / \mathrm{Mk}$

- $\mathrm{rl}=12$ inch $=0.304 \mathrm{~m}$

- $\mathrm{K}$ aluminum cladding $=0.05 \mathrm{~W} / \mathrm{Mk}$

- $\mathrm{D} 2=26$ inch $=0.660 \mathrm{~m}$

- $\mathrm{r} 2=13$ inch $=0.330 \mathrm{~m}$

- $\mathrm{D} 3=29$ inch $=0.736 \mathrm{~m}$

- $\mathrm{r} 3=14.5$ inch $=0.368 \mathrm{~m}$

- $\mathrm{Ti}=513^{\circ} \mathrm{K}$

- $\mathrm{hi}=35 \mathrm{~W} / \mathrm{mK}$

- $\mathrm{To}=291^{\circ} \mathrm{K}$

- ho $=9.5 \mathrm{~W} / \mathrm{mK}$

Perhitungan:

$$
\begin{aligned}
\mathrm{U}_{0} & =\frac{1}{\frac{\mathrm{m}}{\mathrm{rihi}}+\frac{\mathrm{mln}(\mathrm{r} 2 / \mathrm{rl})}{\mathrm{Kpipa}}+\frac{\mathrm{mln}(\mathrm{m} / \mathrm{r} 2)}{\mathrm{Kal}}+\frac{1}{\mathrm{ho}}} \\
& =\frac{1}{\frac{0.368}{0.304 \times 35}+\frac{0.368 \ln (0.330 / 0.304)}{0.05}+\frac{0.368 \ln (0.368 / 0.330)}{0.05}+\frac{1}{9.5}} \\
& =\frac{1}{0.034+0.603+0.802+0.105} \\
& =0.647 \mathrm{~W} / \mathrm{mK} \\
\frac{\mathrm{q}}{\mathrm{A}} & =\mathrm{U} 0(\mathrm{Ti}-\mathrm{To}) \\
& =0.647(591-291) \\
& =0.647 \times 222 \\
& =143.634 \mathrm{~W} / \mathrm{mK} \\
\frac{\mathrm{q}}{\mathrm{L}} & =2 \pi \mathrm{r} 2(\mathrm{Ti}-\mathrm{To}) \mathrm{Uo} \\
& =2 \times 3.14 \times 0.330 \times(513-291) \times 0.647 \\
& =2 \times 3.14 \times 0.330 \times 222 \times 0.647 \\
& =297.667 \mathrm{~W} / \mathrm{m} \\
\frac{\mathrm{q}}{\mathrm{L}} & =297.667 \mathrm{~W} / \mathrm{m} \\
\mathrm{q} & =297.667 \mathrm{~W} / \mathrm{m} \times 1052 \mathrm{~m} \\
& =313145.684 \mathrm{Watt}
\end{aligned}
$$

Pipa diameter 30 inch dan panjang 1428 m; Diketahui:

- $\mathrm{D} 1=30 \mathrm{inch}=0.762$

- $\mathrm{K}$ pipa $=0.05 \mathrm{~W} / \mathrm{mK}$

- $\mathrm{r} 1=15$ inch $=0.381 \mathrm{~m}$

- $\mathrm{K}$ aluminum cladding $=0.05 \mathrm{~W} / \mathrm{mK}$

- $\mathrm{D} 2=32$ inch $=0.812 \mathrm{~m}$

- $\mathrm{r} 2=16$ inch $=0.406 \mathrm{~m}$

- $\mathrm{D} 3=35$ inch $=0.889 \mathrm{~m}$

- $\mathrm{r} 3=17.5$ inch $=0.444 \mathrm{~m}$

- $\mathrm{Ti}=513^{\circ} \mathrm{K}$

- $\mathrm{hi}=35 \mathrm{~W} / \mathrm{mK}$

- $\mathrm{To}=291^{\circ} \mathrm{K}$

- ho $=9.5 \mathrm{~W} / \mathrm{mK}$

Perhitungan: 


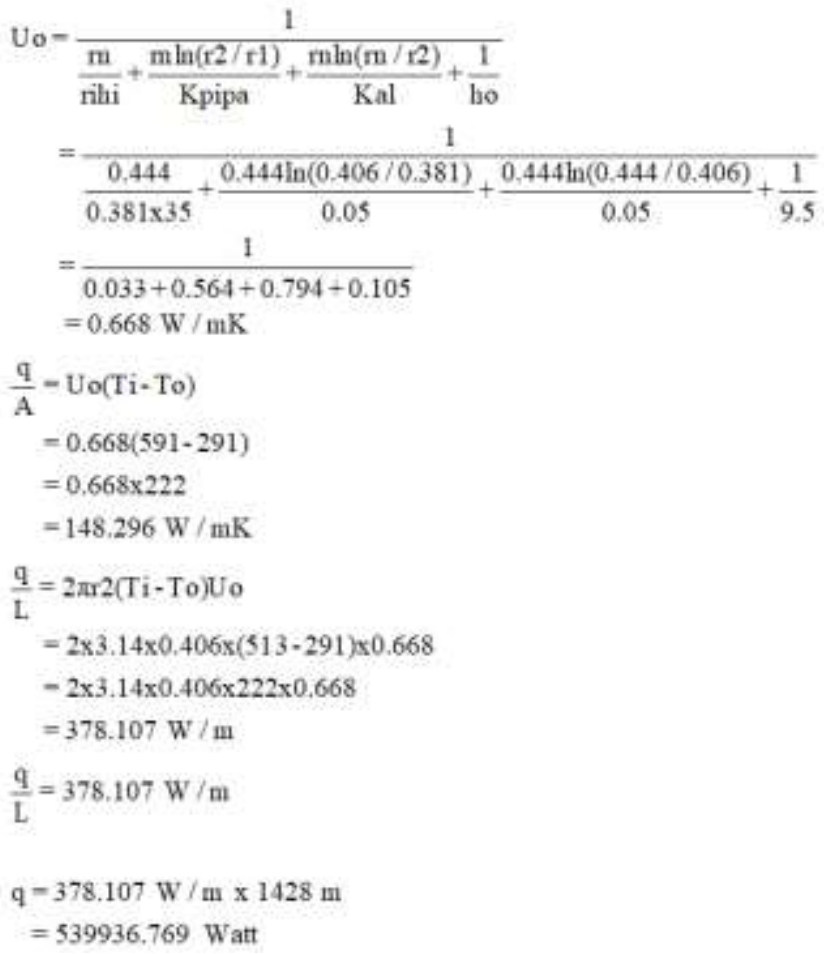

Pipa diameter 36 inch dan panjang 1498; Diketahui:

- $\mathrm{D} 1=36$ inch $=0.914 \mathrm{~m}$

- $\mathrm{K}$ pipa $=0.05 \mathrm{~W} / \mathrm{mK}$

- $\mathrm{r} 1=18$ inch $=0.457 \mathrm{~m}$

- $\mathrm{K}$ aluminum cladding $=0.05 \mathrm{~W} / \mathrm{mK}$

- $\mathrm{D} 2=38$ inch $=0.965 \mathrm{~m}$

- $\mathrm{r} 2=19$ inch $=0.482 \mathrm{~m}$

- $\mathrm{D} 3=41 \mathrm{inch}=1.041 \mathrm{~m}$

- $\mathrm{r} 3=20.5$ inch $=0.520 \mathrm{~m}$

- $\mathrm{Ti}=513^{\circ} \mathrm{K}$

- $\mathrm{hi}=35 \mathrm{~W} / \mathrm{mK}$

- $\mathrm{To}=291^{\circ} \mathrm{K}$

- ho $=9.5 \mathrm{~W} / \mathrm{mK}$

Perhitungan:

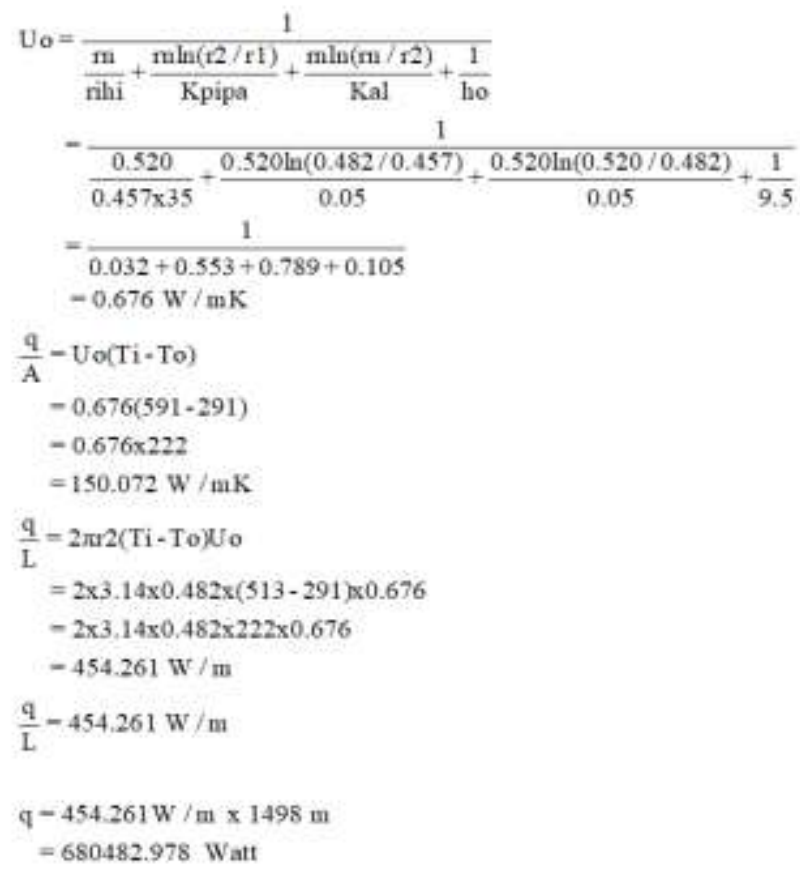

b) Rugi-rugi panas bahan isolasi calcium silicate

> Pipa diameter 20 inch dan panjang 1622 m;

Diketahui:

- $\mathrm{D} 1=20$ inch $=0.508 \mathrm{~m}$

- $\mathrm{K}$ pipa $=0.05 \mathrm{~W} / \mathrm{mK}$

- $\mathrm{K}$ calcium silicate $=0.045 \mathrm{~W} / \mathrm{mK}$

- $\mathrm{r} 1=10 \mathrm{inch}=0.254 \mathrm{~W} / \mathrm{mK}$

- $\mathrm{D} 2=22$ inch $=0.558 \mathrm{~m}$

- $\mathrm{r} 2=11 \mathrm{inch}=0.279 \mathrm{~m}$

- $\mathrm{D} 3=25$ inch $=0.635 \mathrm{~m}$

- $\mathrm{r} 3=12.5$ inch $=0.317 \mathrm{~m}$

- $\mathrm{Ti}=513^{\circ} \mathrm{K}$

- $\mathrm{hi}=35 \mathrm{~W} / \mathrm{mK}$

- $\mathrm{To}=291^{\circ} \mathrm{K}$

- ho $^{2} 9.5 \mathrm{~W} / \mathrm{mK}$

Perhitungan:

$$
\begin{aligned}
\text { Uo } & =\frac{1}{\frac{\mathrm{m}}{\text { rihi }}+\frac{\mathrm{mln}(\mathrm{r} 2 / \mathrm{r} 1)}{\mathrm{Kpipa}}+\frac{\mathrm{mln}(\mathrm{m} / \mathrm{r} 2)}{\mathrm{Kcal}}+\frac{1}{\mathrm{ho}}} \\
& =\frac{1}{\frac{0.317}{0.254 \times 35}+\frac{0.317 \ln (0.279 / 0.254)}{0.05}+\frac{0.317 \ln (0.317 / 0.279)}{0.045}+\frac{1}{9.5}} \\
& =\frac{1}{0.035+0.595+0.899+0.105} \\
& =0.611 \mathrm{~W} / \mathrm{mK} \\
\frac{\mathrm{q}}{\mathrm{A}} & =\mathrm{Uo}(\mathrm{Ti}-\mathrm{To}) \\
& =0.611(591-291) \\
& =0.611 \times 222 \\
& =135.642 \mathrm{~W} / \mathrm{mK} \\
\frac{\mathrm{q}}{\mathrm{L}} & =2 \pi \mathrm{rr} 2(\mathrm{Ti}-\mathrm{To}) \mathrm{Uo} \\
& =2 \times 3.14 \times 0.279 \times(513-291) \times 0.611 \\
& =2 \times 3.14 \times 0.279 \times 222 \times 0.611 \\
& =237.661 \mathrm{~W} / \mathrm{m} \\
\frac{\mathrm{q}}{\mathrm{L}} & =237.661 \mathrm{~W} / \mathrm{m} \\
\mathrm{q} & =237.661 \mathrm{~W} / \mathrm{m} \times 1622 \mathrm{~m} \\
& =385486.142 \mathrm{Watt}
\end{aligned}
$$

Pipa diameter 24 inch dan panjang 1052 m; Diketahui:

- $\mathrm{D} 1=24$ inch $=0.609 \mathrm{~m}$

- $\mathrm{K}$ pipa $=0.05 \mathrm{~W} / \mathrm{mK}$

- $\mathrm{K}$ calcium silicate $=0.045 \mathrm{~W} / \mathrm{mK}$

- $\mathrm{r} 1=12$ inch $=0.304 \mathrm{~m}$

- $\mathrm{D} 2=26$ inch $=0.660 \mathrm{~m}$

- $\mathrm{r} 2=13$ inch $=0.330$

- $\mathrm{D} 3=29$ inch $=0.736 \mathrm{~m}$

- $\mathrm{r} 3=14.5$ inch $=0.368 \mathrm{~m}$

- $\mathrm{Ti}=513^{\circ} \mathrm{K}$

- $\mathrm{hi}=35 \mathrm{~W} / \mathrm{mK}$ 
- $\quad$ To $=291^{\circ} \mathrm{K}$

- ho $^{2} 9.5 \mathrm{~W} / \mathrm{mK}$

Perhitungan:

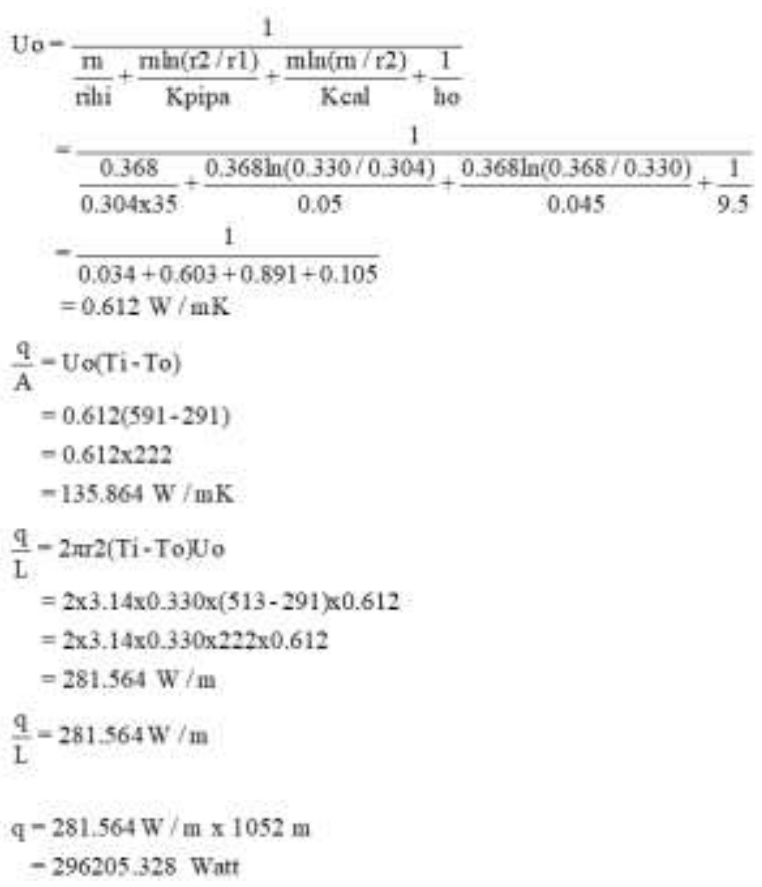

$>\quad$ Pipa diameter 30 inch dengan panjang 1428 m;

Diketahui:

- $\mathrm{D} 1=30$ inch $=0.762 \mathrm{~m}$

- $\mathrm{K}$ pipa $=0.05 \mathrm{~W} / \mathrm{mK}$

- $\mathrm{K}$ calcium silicate $=0.045 \mathrm{~W} / \mathrm{mK}$

- $\mathrm{r} 1=15 \mathrm{inch}=0.381 \mathrm{~m}$

- $\mathrm{D} 2=32$ inch $=0.812 \mathrm{~m}$

- $\mathrm{r} 2=16 \mathrm{inch}=0.406 \mathrm{~m}$

- $\mathrm{D} 3=35$ inch $=0.889 \mathrm{~m}$

- $\mathrm{r} 3=17.5 \mathrm{inch}=0.444 \mathrm{~m}$

- $\mathrm{Ti}=513^{\circ} \mathrm{K}$

- $\mathrm{hi}=35 \mathrm{~W} / \mathrm{mK}$

- $\mathrm{To}=291^{\circ} \mathrm{K}$

- ho $^{2} 9.5 \mathrm{~W} / \mathrm{mK}$

Perhitungan:

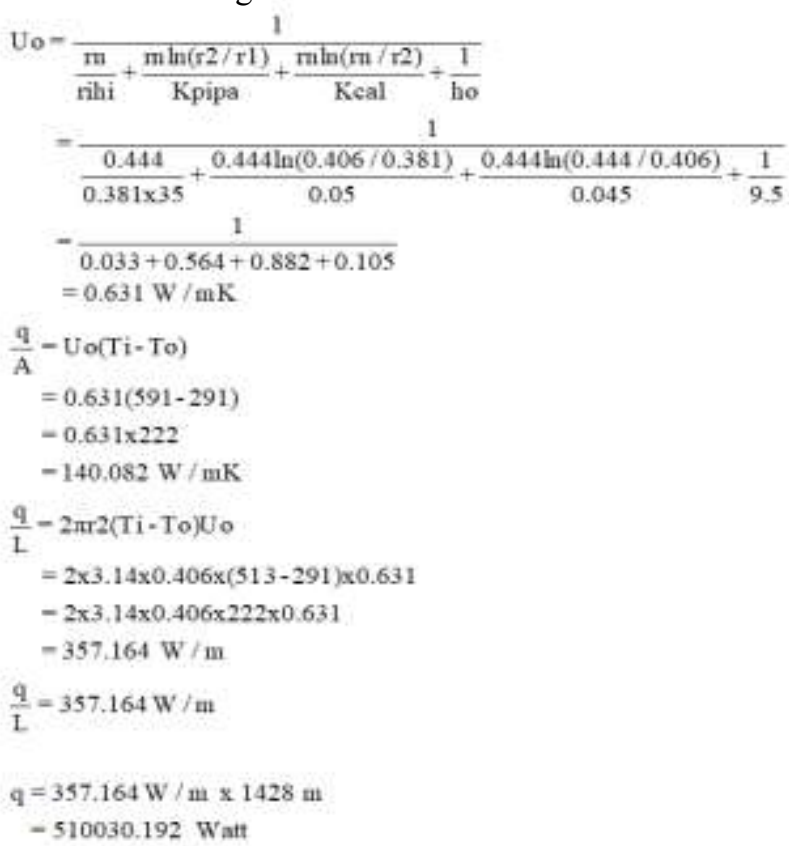




\section{Perhitungan:}

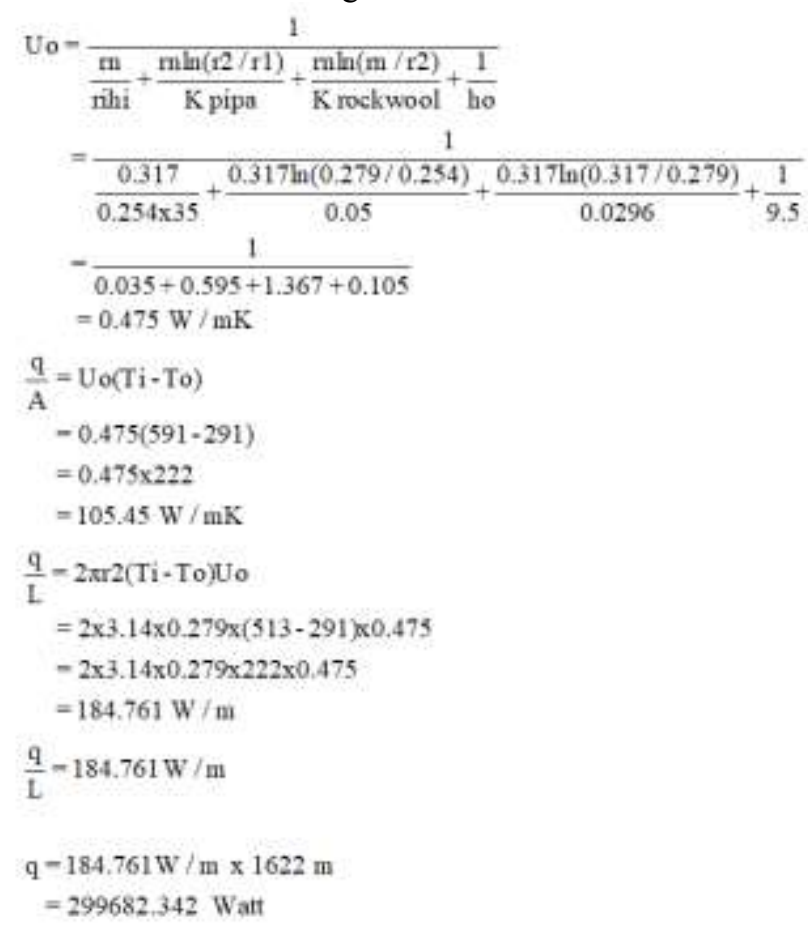

Pipa diameter 24 inch dan panjang 1052 m; Diketahui:

- $\mathrm{D} 1=24$ inch $=0.609 \mathrm{~m}$

- $\mathrm{K}$ pipa $=0.05 \mathrm{~W} / \mathrm{mK}$

- $\mathrm{K}$ rockwool $=0.0296 \mathrm{~W} / \mathrm{mK}$

- $\mathrm{r} 1=12$ inch $=0.304 \mathrm{~m}$

- $\mathrm{D} 2=26$ inch $=0.660 \mathrm{~m}$

- $\mathrm{r} 2=13$ inch $=0.330 \mathrm{~m}$

- $\mathrm{D} 3=29$ inch $=0.736 \mathrm{~m}$

- $\mathrm{r} 3=14.5$ inch $=0.368 \mathrm{~m}$

- $\mathrm{Ti}=513^{\circ} \mathrm{K}$

- $\mathrm{hi}=35 \mathrm{~W} / \mathrm{mK}$

- $\mathrm{To}=291^{\circ} \mathrm{K}$

- ho $^{2} 9.5 \mathrm{~W} / \mathrm{mK}$

Perhitungan:

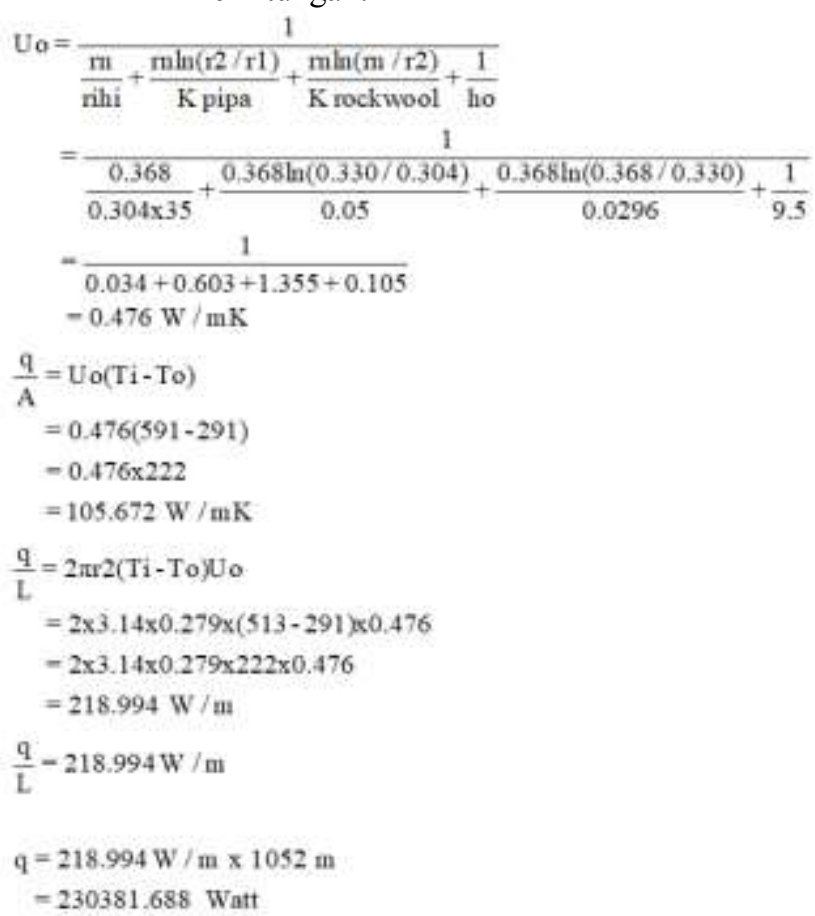

Pipa dengan diameter 30 inch dan panjang $1428 \mathrm{~m}$;

Diketahui:

- $\mathrm{D} 1=30$ inch $=0.762 \mathrm{~m}$

- $\mathrm{K}$ pipa $=0.05 \mathrm{~W} / \mathrm{mK}$

- $\mathrm{K}$ rockwool $=0.0296 \mathrm{~W} / \mathrm{mK}$

- $\mathrm{r} 1=15$ inch $=0.381 \mathrm{~m}$

- $\mathrm{D} 2=32$ inch $=0.812 \mathrm{~m}$

- $\mathrm{r} 2=16$ inch $=0.406 \mathrm{~m}$

- $\mathrm{D} 3=35$ inch $=0.889 \mathrm{~m}$

- $\mathrm{r} 3=17.5 \mathrm{inch}=0.444 \mathrm{~m}$

- $\mathrm{Ti}=513^{\circ} \mathrm{K}$

- $\mathrm{hi}=35 \mathrm{~W} / \mathrm{mK}$

- $\mathrm{To}=291^{\circ} \mathrm{K}$

- $\mathrm{ho}=9.5 \mathrm{~W} / \mathrm{mK}$

Perhitungan:

$$
\begin{aligned}
& \mathrm{Uo}_{0}=\frac{1}{\frac{\mathrm{m}}{\mathrm{rhi}}+\frac{\mathrm{mln}(\mathrm{r} 2 / \mathrm{rl})}{\mathrm{K} \text { pipa }}+\frac{\mathrm{mln}(\mathrm{m} / \mathrm{r} 2)}{\mathrm{K} \text { rockwool }}+\frac{1}{\text { ho }}} \\
& =\frac{1}{\frac{0.444}{0.381 \times 35}+\frac{0.444 \ln (0.406 / 0.381)}{0.05}+\frac{0.444 \ln (0.444 / 0.406)}{0.0296}+\frac{1}{9.5}} \\
& =\frac{1}{0.033+0.564+1.342+0.105} \\
& =0.489 \mathrm{~W} / \mathrm{mK} \\
& \frac{\mathrm{q}}{\mathrm{A}}=\mathrm{Uo}(\mathrm{Ti}-\mathrm{To}) \\
& =0.489(591-291) \\
& =0.489 \times 222 \\
& =108.558 \mathrm{~W} / \mathrm{mK} \\
& \frac{\mathrm{q}}{\mathrm{L}}-2 \pi \mathrm{r} 2(\mathrm{Ti}-\mathrm{To}) \mathrm{Uo} \\
& =2 \times 3.14 \times 0.279 \times(513-291) \times 0.489 \\
& =2 \times 3.14 \times 0.279 \times 222 \times 0.489 \\
& =276.788 \mathrm{~W} / \mathrm{m} \\
& \frac{\mathrm{q}}{\mathrm{L}}=276,788 \mathrm{~W} / \mathrm{m} \\
& \mathrm{q}=276.788 \mathrm{~W} / \mathrm{m} \times 1428 \mathrm{~m} \\
& =395253.264 \text { Wart }
\end{aligned}
$$

Pipa dengan diameter 36 inch dan panjang $1498 \mathrm{~m}$;

Diketahui:

- $\mathrm{D}=36$ inch $=0.914 \mathrm{~m}$

- $\mathrm{K}$ pipa $=0.05 \mathrm{~W} / \mathrm{mK}$

- $\mathrm{K}$ rockwool $=0.0296 \mathrm{~W} / \mathrm{mK}$

- $\mathrm{r} 1=18$ inch $=0.457 \mathrm{~m}$

- $\mathrm{D} 2=38$ inch $=0.965 \mathrm{~m}$

- $\mathrm{r} 2=19$ inch $=0.482 \mathrm{~m}$

- $\mathrm{D} 3=41 \mathrm{inch}=1.041 \mathrm{~m}$

- $\mathrm{r} 3=20.5$ inch $=0.520 \mathrm{~m}$

- $\mathrm{Ti}=513^{\circ} \mathrm{K}$

- $\mathrm{hi}=35 \mathrm{~W} / \mathrm{mK}$

- $\mathrm{To}=291^{\circ} \mathrm{K}$

- ho $=9.5 \mathrm{~W} / \mathrm{mK}$ 


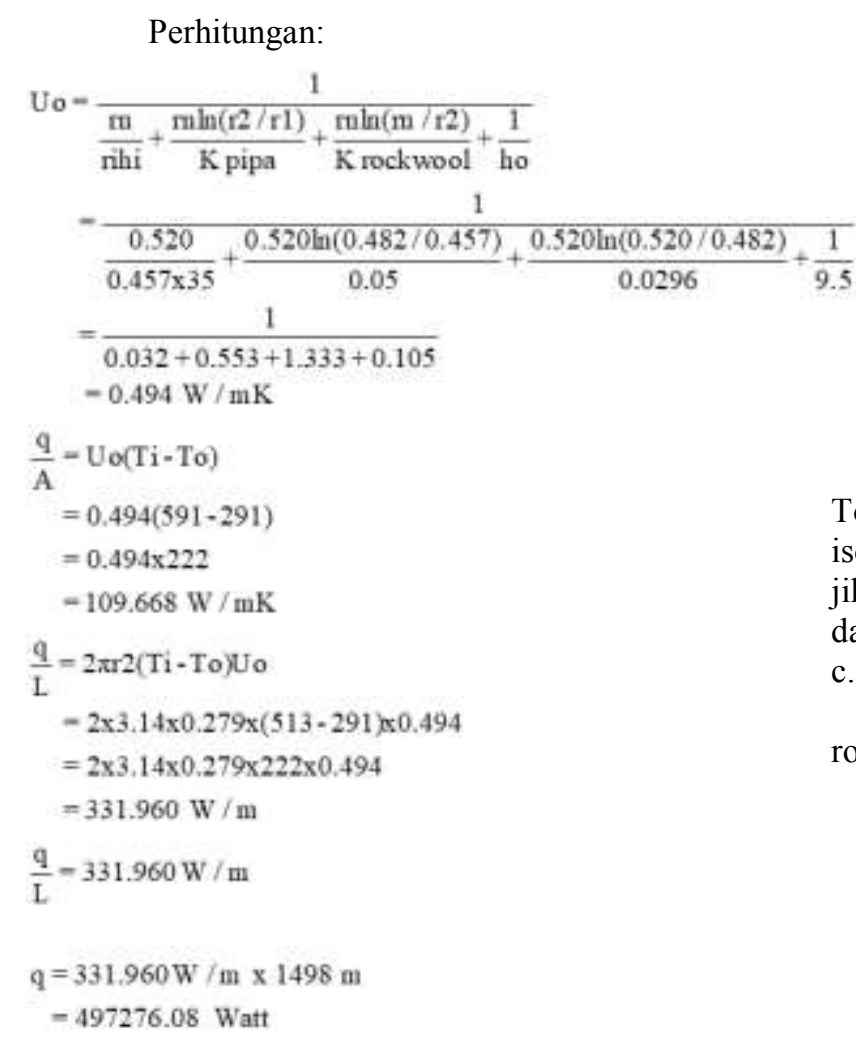

\section{B. Faktor ekonomis penggantian isolasi pipa}

Jika dalam 8 tahun beroperasi maka total kerugian pendapatannya adalah 20.800.000 USD, maka dari itu untuk membandingkan kerugian pendapatan dari memakai bahan isolasi aluminium cladding, calcium silicate, rockwool tujuannya adalah agar dapat mengetahui bahan yang dapat disarankan ke perusahaan [9].

a. Bahan isolasi aluminium cladding

Perhitungan kerugian pendapatan untuk bahan isolasi alumunium cladding yakni:

\section{Kerugian Per Meter$$
\$=\frac{408199+313145+539936+680482}{2600000}
$$$$
=0.746 \mathrm{Watt} / \mathrm{tahum}
$$

\section{Total Kerugian}

$$
\begin{aligned}
S \text { total } & =0.746 \times 20.800 .000 \\
& =15.516 .800 \mathrm{USD}
\end{aligned}
$$

Total kerugian pendapatan dengan memakai bahan isolasi aluminium cladding adalah 15.516.800 USD atau jika dirupiahkan adalah sekitar 218 miliar rupiah dalam kurun waktu 8 tahun beroperasi.

b. Bahan isolasi calcium silicate

Perhitungan kerugian pendapatan untuk bahan isolasi calcium silicate yakni:

\section{Kerugian Per Meter}

$$
\begin{aligned}
\mathbb{S} & =\frac{385486+296205+510030+642231}{2600000} \\
& =0.694 \mathrm{Watt} / \mathrm{tahun}
\end{aligned}
$$

\section{Total Kerugian}

$$
\begin{aligned}
\$ \text { total } & =0.694 \times 20.800 .000 \\
& =14.435 .200 \mathrm{USD}
\end{aligned}
$$

Total kerugian pendapatan dengan memakai bahan isolasi calcium silicate adalah 14.435.200 USD atau jika dirupiahkan adalah sekitar 202 miliar rupiah dalam kurun waktu 8 tahun beroperasi.

c. Bahan Isolasi Rockwool

Perhitungan kerugian pendapatan intuk bahan isolasi rockwool yakni:

$$
\begin{aligned}
& \text { Kerugian Per Meter } \\
& \begin{aligned}
\mathbb{S} & =\frac{299682+230381+395253+497276}{2600000} \\
& =0.547 \mathrm{Watt} / \text { tahum }
\end{aligned}
\end{aligned}
$$

\section{Total Kerugian}

$\$$ total $=0.547 \times 20.800,000$

$$
=11.377 .600 \mathrm{USD}
$$

Total kerugian pendapatan dengan memakai bahan isolasi rockwool adalah 11.377.600 USD atau jika dirupiahkan adalah sekitar 160 miliar rupiah dalam kurun waktu 8 tahun beroperasi [10].

C. Perbandingan kerugian total bahan isolasi

Setelah diketahui kerugian pendapatan dari kedua bahan isolasi dapat diperoleh perbandingan antara kerugian bahan isolasi lama yaitu aluminium cladding dan bahan isolasi baru calcium silicate dan rockwool, seperti ditunjukkan pada tabel 2.

Tabel 2. Data kerugian bahan isolasi

\begin{tabular}{ccc}
\hline Bahan Isolasi & $\begin{array}{c}\text { Total Rugi-rugi } \\
\text { panas Yang } \\
\text { Hilang }\end{array}$ & $\begin{array}{c}\text { Total } \\
\text { Kerugian } \\
\text { Pendapatan }\end{array}$ \\
\hline $\begin{array}{c}\text { Alumunium } \\
\text { Cladding } \\
(\mathrm{K}=0.05\end{array}$ & $1.941 .762 \mathrm{Watt}$ & $\begin{array}{c}15.516 .800 \\
\text { USD }\end{array}$ \\
$\mathrm{W} / \mathrm{mK})$ & & \\
\hline $\begin{array}{c}\text { Calcium } \\
\text { Silicate }\end{array}$ & $1.833 .952 \mathrm{Watt}$ & $\begin{array}{c}14.435 .200 \\
\mathrm{USD}\end{array}$ \\
$\begin{array}{c}\mathrm{K}=0.045 \\
\mathrm{~W} / \mathrm{mK})\end{array}$ & & \\
\hline $\begin{array}{c}\text { Rockwool } \\
(\mathrm{K}=0.0296\end{array}$ & $1.422 .592 \mathrm{Watt}$ & 11.377 .600 \\
$\mathrm{~W} / \mathrm{mK})$ & & $\mathrm{USD}$ \\
\hline
\end{tabular}


a) Perbandingan kerugian bahan isolasi alumunium cladding dan calcium cilicate

Perhitungan perbandingan kerugian isolasi alumunium cladding dan calcium silicate yakni:

$$
15.516 .800-14.435 .200=1.081 .600 \text { USD }
$$

Maka diketahui kerugian yang dapat diminimalisir adalah 1.081.600 USD atau sekitar 15 miliar.

b) Perbandingan kerugian bahan isolasi alumunium cladding dan rockwool

Perhitungan perbandingan kerugian isolasi alumunium cladding dan rockwool yakni:

$$
\begin{gathered}
=15.516 .800-11.377 .600=4.139 .200 \\
\text { USD }
\end{gathered}
$$

Maka dapat diketahui perbandingan kerugian kerugian yang dapat diminimalisir adalah 4.139.200 USD atau sekitar 58 miliar rupiah.

Berdasar hasil penelitan ini disarankan memakai bahan pengganti isolasi yaitu bahan isolasi rockwool dengan $\mathrm{K}=0.0269 \mathrm{~W} / \mathrm{mK}$ dan bahan isolasi calcium silicate dengan $\mathrm{K}=0.045 \mathrm{~W} / \mathrm{mK}$. Bahan isolasi rockwool memiliki kelebihan yakni meminimalisir rugi-rugi panas yang hilang, serta kerugian pendapatan dalam kurun waktu 8 tahun beroperasi. Sedangkan kekurangan bahan isolasi rockwool yakni mudah terbakar, instalasinya cukup sulit karena menggulung terlebih dahulu ke pipa yang akan diisolasi, dan dapat membuat iritasi kulit jika tersentuh. Bahan isolasi calcium silicate memiliki kelebihan pada intsalasinya yang mudah karena hanya tinggal menyusaikan pipa yang akan di isolasi kemudian pasang, tahan lama pada lingkungan dingin, dan umur pakai yang lebih lama daripada bahan isolasi rockwool. Sedangkan kekurangan bahan isolasi calcium silicate yakni reduksi rugi-rugi panas yang tidak sebaik rockwool sehingga reduksi kerugian pendapatan perusahaan dalam kurun waktu 8 tahun beroperasi juga tidak sebesar bahan isolasi rockwool.

\section{KESIMPULAN}

1. Jumlah kehilangan panas total dalam kurun waktu 8 tahun dengan memakai bahan isolasi lama yaitu aluminium cladding dengan $\mathrm{K}=$ $0.05 \mathrm{~W} / \mathrm{mK}$ adalah 1.941.762 Watt.

2. Jumlah kehilangan panas total jika dalam kurun waktu 8 tahun dengan memakai bahan isolasi calcium silicate dengan $\mathrm{K}=0.045 \mathrm{~W} / \mathrm{mK}$ adalah 1.833.952 Watt.

3. Jumlah kehilangan panas total jika dalam kurun waktu 8 tahun dengan memakai bahan isolasi rockwool dengan $\mathrm{K}=0.0296 \mathrm{~W} / \mathrm{mK}$ adalah 1.422.592 Watt.
4. Total kerugian pendapatan dalam kurun waktu 8 tahun beroperasi dengan menggunakan bahan isolasi aluminium cladding adalah 15.516.800 USD atau sekitar 218 miliar rupiah.

5. Total kerugian pendapatan dalam kurun waktu 8 tahun beroperasi dengan menggunakan bahan isolasi calcium silicate adalah 14.435.200 USD atau sekitar 202 miliar rupiah.

6. Total kerugian pendapatan dalam kurun waktu 8 tahun beroperasi dengan menggunakan bahan isolasi rockwool adalah 11.377.600 USD atau sekitar 160 miliar rupiah.

7. Kerugian pendapatan yang dapat diminimalisir jika memakai bahan isolasi calcium silicate adalah 1.081.600 USD atau sekitar 15 miliar rupiah dalam kurun waktu 8 tahun beroperasi.

8. Kerugian pendapatan yang dapat diminimalisir jika memakai bahan isolasi calcium silicate adalah 4.139.200 USD atau sekitar 58 miliar rupiah dalam kurun waktu 8 tahun beroperasi.

9. Bahan isolasi pengganti rockwool dan calcium silicate direkomendasikan karena sesuai dengan service temperature pada pipa. Sedangkan bahan isolasi perlite tidak disarankan karena bahan isolaso perlite diperuntukkan pada pipa yang memiliki service temperature yang lebih tinggi.

10. PLTP Darajat direkomendasikan menggunakan bahan isolasi pengganti yaitu rockwool dengan $\mathrm{K}=0.0296 \mathrm{~W} / \mathrm{mK}$ yang dapat meminimalisir kerugian pendapatan dalam kurun waktu 8 tahun beroperasi.

\section{REFERENSI}

[1] Y. A. Cangel and A. J. Ghajar, Mass and heat transfer fundamental and application. 2015.

[2] Muntolib dan Rusdiyantoro, Analisa bahan isolasi pipa pada boiler untuk meminimalisasi heat loss, Jurnal Teknik WAKTU, vol. 12, pp. 50-56, 2014.

[3] L. Buchori, Perpindahan panas (heat transfer) bagian I, Bahan Ajar Perpindahan Panas Bagian I, p. 94, 2003.

[4] J. R. Culham, M. M. Yovanovich, and P. Teertstra, Analytical forced convection modelling of plate fin heat sinks, Fifteenth Annual IEEE Semiconductor Thermal Measurement and Management Symposium, San Diego, 9-11 Maret 1999, DOI: 10.1109/STHERM.1999.762426.

[5] Ali Hasimi Pane, Perpindahan panas kondisi steady state-one dimensional, ALP Consultant, 2015, pp. 12-34.

[6] Sularso, Dasar perencanaan dan pemilihan elemen mesin. Association for International Technical Promotion, 1978.

[7] H. Struchtrup, Thermodynamics and energy conversion, Springer, 2014.

[8] K. Taugbøl, J. O. Brevik, B. Rudshaug, and E. Asa, Automatic drilling fluid measurements methods for measuring density and rheology of drilling fluids," SPE Drilling \& Completion, vol. 24, issue 04, 2009, pp. 22-24, DOI: 10.2118/112687-PA.

[9] M. Plooij and M. Wisse, "A novel spring mechanism to reduce energy consumption of robotic arms," IEEE 
Int. Conf. Intell. Robot. Syst., pp. 2901-2908, 2012, doi: 10.1109/IROS.2012.6385488.

[10] Fadhli and I. Syahputra, Identifikasi potensi Pembangkit Listrik Tenaga Hybrid (PLTH) angin dan surya di kabupaten Aceh Besar, Jurnal Teknik Sipil Unaya, vol. 5, no. 2, 2019, pp. 39-47. 